\title{
FORTIFICATION OF YOGURT WITH $\beta$-GLUCANS FROM OYSTER MUSHROOM
}

\author{
Ekaterina Antontceva ${ }^{1}$, Tatyana Belyakova ${ }^{2}$, Lyudmila Zabodalova ${ }^{2}$, Mark Shamtsyan ${ }^{1 *}$ \\ ${ }^{I}$ Department of Technology of Microbiological Synthesis, Faculty of Chemical and Biotechnology, Saint Petersburg State Institute of \\ Technology, 26 Moskovsky Prospect, Saint Petersburg, Russia, e-mail: mark.shamtsyan@yandex.ru \\ ${ }^{2}$ Faculty of Food Biotechnologies and Engineering, St. Petersburg National Research University of Information Technologies, \\ Mechanics and Optics (ITMO UNIVERSITY), 9 Lomonosova Street, Saint Petersburg, Russia
}

\begin{abstract}
Mushrooms are a good source of biologically active substances. Basidiomycete Pleurotus ostreatus is not only widely used in food, but also have immunomodulating, antitumor, antiradical, anti-inflammatory, hypocholesterolic, hypoglycaemic and other beneficial medical effects. It is considered that $\beta$-glucans play significant role in the biological activities of the oyster mushroom. The aim of this research was to study the effect of the addition of various $\beta$-glucan containing preparations obtained from the submerged biomass of $P$. ostreatus on the process of milk fermentation in the production of yogurt and properties of the finished product. A total of three preparations were obtained by successive ethanolic and aqueous extractions. Preparations were added to milk in different concentrations before the introduction of starter culture. A starter containing Streptococcus thermophilus and Lactobacillus delbuckii subsp. bulgaricus cultures was used for fermentation. The titratable and active acidity was controlled during the fermentation. Physicochemical, structural-mechanical properties (dynamic viscosity, viscosity loss factor, mechanical stability factor, structure recovery ratio) of the obtained samples were studied. The sensory properties of the products were also evaluated. Results show that the addition of preparations does not adversely affect the fermentation process. Structural-mechanical properties of yogurt samples fortified by $\beta$-glucan-containing preparations depend on the preparation and its concentration. Sensory evaluation showed that experimental samples differed not only from the control sample but also from each other. In order to exclude slightly negative effect of some of the introduced components on the sensory characteristics of the product, it is advisable to use thickeners and structure-formers, for example, pectin.
\end{abstract}

Keywords: Pleurotus ostreatus, $\beta$-glucans, functional food, fermented milk product

\section{Introduction}

Fungi are a promising source of natural biologically active substances. For a large number of species and genera of various fungi, significant immunostimulant activity was detected (Vannucci et al., 2013). The polysaccharides of basidiomycetes, in particular $\beta$-glucans, are of considerable interest to researchers due to various useful properties (Bashir, Choi, 2017). The oyster mushroom Pleurotus ostreatus is widely cultivated throughout the world, and in addition to direct consumption it can also be an excellent source of various biologically active substances (Carrasco-González et al., 2017; Khan, Tania, 2012).

Polysaccharides obtained from P. ostreatus possess a wide range of biological activity in vivo and in vitro (Llauradó et al., 2015; Pasnik et al., 2017; Radzki et al., 2016). Thus, the hypolipidemic and hypocholesterol effect of oral consumption of dry biomass of P. ostreatus was shown (Shamtsyan at al., 2014).

Aqueous extracts from the fruit bodies of the $P$. ostreatus demonstrated a significant immunostimulatory effect: activating various immunocompetent cells, stimulating neutrophils of human peripheral blood, increasing production of interleukin 1- $\beta$, proinflammatory cytokines, etc. (Jesenak et al., 2013; Novak, Vetvicka, 2008).

Purified water-soluble heteropolysaccharides obtained by hot water extraction from the fruiting bodies of the $P$. ostreatus showed a strong antitumor effect on Hela cells and did not have direct cytotoxicity with respect to noncancerous cells (Tong et al., 2009). In other studies, the efficacy of water-insoluble fractions of P. ostreatus polysaccharides against Sarcoma 180 in vivo was studied. The studied polysaccharide preparations showed a decrease in the volume and mass of tumours (Facchini et al., 2014). It is believed that polysaccharides isolated from $P$. ostreatus can be used to develop new functional products (Giavasis, 2014; Lavelli et al., 2018). When incorporated into products, such preparation can provide additional prophylactic and functional properties, such as immunostimulant, hypoglycaemic, anti-radical, antitumor, anti-inflammatory and others (Khan et al., 2017).

Yogurt is a functional food product containing probiotic cultures and amino acids (Antontceva et al., 2018). Many manufacturers enrich yogurts with various vitamins, minerals and natural flavour additives (Vital et al., 2015). In recent years, the fortification of various food products, including pasta, flakes, cereals, bakery products, beverages, and dairy products with plant $\beta$-glucans as dietary fibre, has been actively studied (Bhaskar et al., 2017). Also, when giving additional functional properties to the products, it is important at least to preserve the initial physicochemical, rheological and sensory properties. Many studies have shown the possibility of using $\beta$-glucans from different sources as thickeners, texturizers and even fat replacers (Khorshidian et al., 2018; Raikos et al., 2018).

Hozova et al. (2004) established that the addition of pleuran (glucan isolated from $P$. ostreatus) hydrogel to yogurt did not inhibit the fermentation ability of yoghurt cultures and had no negative influence on the sensory acceptability (appearance, colour, consistency, taste) of the products. The $\mathrm{pH}$ of samples showed values typical 
for this kind of product during a month-lasting storage. Authors suggested that the regular daily consumption of the innovative milk products with the application of an average dose of $\beta$-glucans, i.e. $5 \mathrm{mg}$ per $150 \mathrm{~mL}$ yoghurt, would contribute to the reduction of the occurrence of relapsing or chronic infectious as well as autoimmune and oncological diseases.

$P$. ostreatus aqueous extract improved rheological properties and texture characteristics (lower firmness but higher cohesiveness, adhesiveness, springiness and less syneresis) of low-fat yogurt. Supplemented yogurts were darker, contained more polyphenols and exhibited higher antioxidant activity than controls in cold storage (Vital et al., 2015). In our previous study biomass of $P$. ostreatus treated with ethanol was introduced into low-fat yogurt. The addition of preparation had a positive effect on physical-chemical (titratable and active acidity) and rheological properties of the product (viscosity) during the storage period (Sorokin et al., 2016).

The aim of this research was to study the effect of the addition of various $\beta$-glucan containing preparations obtained from the submerged biomass of $P$. ostreatus on the process of milk fermentation in the production of yogurt and properties of the finished product.

\section{Materials and Methods}

\section{$\beta$-glucan preparations from $P$. ostreatus}

Choosing the type of added preparation and its quantity was based on the results of previous studies (Antontceva et al., 2018).

In the experiment, 3 different preparations obtained from the biomass of the culture P. ostreatus (Jacq.: Fr.) P. Kumm were used:

o preparation P1 is submerged biomass of $P$. ostreatus, treated twice with $80 \%$ ethanol during 3 hours at the temperature $80^{\circ} \mathrm{C}$ to remove ethanol soluble compounds, such as lipids, triterpenes, and some low molecular weight compounds. The preparation contains $33.5 \%$ of water-soluble and water-insoluble $\beta$-glucans. The preparation P1 was introduced in a dosage of 0.1 and $0.25 \%$;

o preparation $\mathrm{P} 2$ is a fraction of components released during water extraction during 3 hours at the temperature of $100{ }^{\circ} \mathrm{C}$ and insoluble in ethanol. The content of water-soluble $\beta$-glucans in the preparation is $23.8 \%$. The preparation $\mathrm{P} 2$ was introduced in a dosage of $0.1 \%$ The effect of this preparation was studied only in lower concentration, as in contrary to other 2 crude preparations it is a purified preparation of water-soluble $\beta$-glucans;

$\circ$ preparation P3 is a precipitate after successive ethanolic and water extraction containing a waterinsoluble fraction: water-insoluble $\beta$-glucans, chitin or chitin-glucan complex and other water-insoluble high-molecular components. The content of $\beta$ glucans in the preparation is $41.2 \%$. The preparation P3 was introduced in a dosage of 0.1 and $0.25 \%$.

The detailed methods of obtaining the preparations has been described by Antontceva et al. (2018).
The content of $\beta$-glucans in preparations was determined using the $\beta$-glucan Assay Kit (Yeast \& Mushroom) (Megazyme, USA) (McCleary, Draga, 2016).

\section{Preparation of yogurt}

Standardized milk (2.5\% fat) and skimmed milk powder ( $1.5 \%$ fat) were mixed in such a proportion that obtained mixture had a mass fraction of dry substances of $9.45 \%$ and protein content of $3.27 \%$. Fat content, mass fraction of dry substances and protein content in mixture and finished product was measured using milk analyser Lactoscan SA (Milkotronic Ltd., Bulgaria). For fermentation a lyophilized concentrated direct starter YO-MIX TM 305 LYO 250 DCU, which includes cultures Streptococcus thermophilus, Lactobacillus delbuckii subsp. bulgaricus (Danisco, Denmark) was used.

Preparations of $\beta$-glucans were introduced at the initial stage of preparing milk mixture in the amount of $0.1-0.25 \%$ of the total volume of the mixture (Table 1 ) at the temperature $30-35{ }^{\circ} \mathrm{C}$ with constant stirring. The mixture was left at rest for 30 minutes to swell, then stirred to a uniform consistency for 10-15 minutes, pasteurization was carried out in a water bath at $85^{\circ} \mathrm{C}$ with 5 min holding time, then cooled to a temperature of $37^{\circ} \mathrm{C}$ and then the starter was introduced. The obtained mixture was stirred for 10 minutes and fermented at $37 \pm 1{ }^{\circ} \mathrm{C}$ temperature for 6 hours until the clot titratable acidity was $100 \pm 2{ }^{\circ} \mathrm{T}$. The control sample of yogurt was prepared without the addition of $\beta$-glucan preparations. The titratable acidity was determined by titration of the samples with $1 \mathrm{~N} \mathrm{NaOH}$ solution using phenolphthalein as the indicator. The $\mathrm{pH}$ value of samples was obtained by using an SG2-ELK SevenGo pH-meter (Mettler Toledo, Switzerland).

Table 1

\begin{tabular}{lcc}
\multicolumn{3}{c}{ Analysed yogurt samples } \\
\hline Yogurt samples & $\begin{array}{c}\text { Type of } \\
\text { preparation }\end{array}$ & $\begin{array}{c}\text { Preparation } \\
\text { concentration, \% }\end{array}$ \\
\hline Control & - & - \\
Experimental P1-0.1\% & P1 & 0.10 \\
Experimental P1-0.25\% & P1 & 0.25 \\
Experimental P2-0.1\% & P2 & 0.10 \\
Experimental P3-0.1\% & P3 & 0.10 \\
Experimental P3-0.25\% & P3 & 0.25 \\
\hline
\end{tabular}

Rheological studies were carried out to identify the effect of the added $\beta$-glucan containing preparations on the structure and consistency of yogurt using a rotational viscometer Rheotest-2 type RV 2 (VEB MLW PRUFGERATE-WERK, Germany). The mass of each test sample was $10 \mathrm{~g}$, the measurement was carried out at a temperature of $20{ }^{\circ} \mathrm{C}$. Samples were subjected to a uniform shear field with a constant gradient of the shear rate of $145.8 \mathrm{~s}^{-1}$ for $2 \mathrm{~min}$, taking readings of the instrument every 15 seconds. According to the results of the measurements the coefficient of dynamic viscosity in the intact structure $\eta_{I}$ (the first measurement), the destroyed structure $\eta_{\mathrm{D}}$ (after 2 min of mechanical impact) and the restored structure $\eta_{R}$ (after 15 min of exposure) were determined. 
Viscosity loss factor (VLF), mechanical stability factor (MSF) and structure recovery ratio (SRR) were calculated by the following equations $1-3$, respectively:

$$
\begin{gathered}
\mathrm{VLF}=\frac{\left(\eta_{\mathrm{I}}-\eta_{\mathrm{D}}\right)}{\eta_{\mathrm{I}}} \times 100 \% \\
M S F=\frac{\eta_{\mathrm{I}}}{\eta_{\mathrm{D}}} \\
S R R=\frac{\eta_{R}}{\eta_{I}} \times 100 \%
\end{gathered}
$$

where: VLF - viscosity loss factor,

MSF - mechanical stability factor,

SRR - structure recovery ratio,

$\eta_{I}-$ coefficient of dynamic viscosity in the intact structure,

$\eta_{D}-$ coefficient of dynamic viscosity of the destroyed structure,

$\eta_{\mathrm{R}}-$ coefficient of dynamic viscosity of the restored structure.

Samples were evaluated for such sensory properties as taste, odour, colour, consistency, and appearance by the blind taste test with participation of trained panel ( 8 panellists, 2 males and 6 females, aged 28-50 years), of the Faculty of Food Biotechnologies and Engineering of ITMO university. According to GOST R ISO (Russian State Standard) 22935-2-2011 "Milk and milk products. Sensory analysis. Part 2. Recommended methods for sensory evaluation" the sensory properties of the product must meet the following requirements: appearance, consistency - homogeneous, moderately viscous; taste and odour - clean, fermented milk without foreign tastes and odours; colour - milky white, uniform. The sensory analysis of the experimental samples was carried out in comparison with the control sample. Indicators were evaluated according to the degree of deviation from the sensory requirements on a five-point scale: 5 - no deviations, $4-$ minimum deviations, 3 - noticeable deviations, 2 - significant deviations, 1 - very significant deviations.

All experiments and measurements were carried out at least in three replicates. Statistical processing of the data was performed using the software Statistica (version 10, Statsoft, USA). The level of confidence was chosen as 0.95 . For the sensory characteristics average results of the sensory scoring evaluation were calculated.

\section{Results and Discussion}

The finished products had the following indicators: $2.5 \%$ fat content and $3.27 \%$ protein content.

The titratable (Table 2) and active (Table 3 ) acidity were measured during the fermentation process.

Table 2

Dynamics of changes in titratable acidity of different yogurt samples

\begin{tabular}{lcccc}
\hline \multirow{3}{*}{ Sample } & \multicolumn{4}{c}{ Titratable acidity, ${ }^{\mathbf{o}} \mathbf{T}$} \\
\cline { 2 - 5 } & \multicolumn{4}{c}{ Duration, $\mathbf{~ h}$} \\
\cline { 2 - 5 } & $\mathbf{0}$ & $\mathbf{2}$ & $\mathbf{4}$ & $\mathbf{6}$ \\
\hline Control & $18 \pm 1$ & $27 \pm 2$ & $82 \pm 2$ & $103 \pm 2$ \\
P1-0.1\% & $18 \pm 2$ & $30 \pm 2$ & $82 \pm 2$ & $103 \pm 1$ \\
P1-0.25\% & $18 \pm 1$ & $28 \pm 1$ & $82 \pm 1$ & $103 \pm 2$ \\
P2-0.1\% & $21 \pm 1$ & $28 \pm 2$ & $79 \pm 1$ & $105 \pm 2$ \\
P3-0.1\% & $21 \pm 2$ & $28 \pm 3$ & $82 \pm 2$ & $100 \pm 2$ \\
P3-0.25\% & $21 \pm 2$ & $27 \pm 2$ & $75 \pm 2$ & $102 \pm 1$ \\
\hline
\end{tabular}

According to the results of the experiment, the fermentation process of samples with the $\beta$-glucan preparations introduced is uniform and practically does not differ from the control $(\mathrm{p}>0.05)$. The required titratable acidity of the test samples $\left(100^{\circ} \mathrm{T}\right)$ was achieved in 6 hours.

Dynamics of changes in active acidity of different yogurt samples

\begin{tabular}{lcccc}
\hline & \multicolumn{4}{c}{ Active acidity (pH) } \\
\cline { 2 - 5 } Sample & \multicolumn{4}{c}{ Duration, h } \\
\cline { 2 - 5 } & $\mathbf{0}$ & $\mathbf{2}$ & $\mathbf{4}$ & $\mathbf{6}$ \\
\hline Control & $6.58 \pm 0.01$ & $6.09 \pm 0.01$ & $4.65 \pm 0.01$ & $4.08 \pm 0.01$ \\
P1-0.1\% & $6.58 \pm 0.02$ & $6.02 \pm 0.02$ & $4.66 \pm 0.01$ & $4.18 \pm 0.02$ \\
P1-0.25\% & $6.58 \pm 0.02$ & $6.03 \pm 0.01$ & $4.57 \pm 0.02$ & $4.18 \pm 0.01$ \\
P2-0.1\% & $6.56 \pm 0.02$ & $6.07 \pm 0.01$ & $4.65 \pm 0.03$ & $4.22 \pm 0.01$ \\
P3-0.1\% & $6.57 \pm 0.01$ & $6.13 \pm 0.01$ & $4.70 \pm 0.01$ & $4.20 \pm 0.02$ \\
P3-0.25\% & $6.52 \pm 0.01$ & $6.14 \pm 0.02$ & $4.72 \pm 0.01$ & $4.31 \pm 0.01$ \\
\hline
\end{tabular}

Table 4

Structural-mechanical properties of yogurt samples

\begin{tabular}{lccc}
\hline \multicolumn{1}{c}{ Sample } & $\begin{array}{c}\text { Viscosity } \\
\text { loss factor, } \\
\text { \% }\end{array}$ & $\begin{array}{c}\text { Mechanical } \\
\text { stability } \\
\text { factor }\end{array}$ & $\begin{array}{c}\text { Structure } \\
\text { recovery } \\
\text { ratio, \% }\end{array}$ \\
\hline Control & $25 \pm 1$ & $1.4 \pm 0.1$ & $71 \pm 1$ \\
P1-0.1\% & $29 \pm 2$ & $1.5 \pm 0.1$ & $69 \pm 2$ \\
P1-0.25\% & $11 \pm 1$ & $1.1 \pm 0.1$ & $79 \pm 2$ \\
P2-0.1\% & $19 \pm 18$ & $1.2 \pm 0.1$ & $77 \pm 1$ \\
P3-0.1\% & $26 \pm 1$ & $1.4 \pm 0.1$ & $75 \pm 1$ \\
P3-0.25\% & $26 \pm 2$ & $1.5 \pm 0.2$ & $70 \pm 3$ \\
\hline
\end{tabular}

Table 4 shows the values of the calculated viscosity loss factor, mechanical stability factor, and structure recovery ratio. These indicators characterize the stability of the structure of the product to mechanical stress and its ability to thixotropic recovery.

Analysing the data given in Table 4, it can be noted that the introduction of preparations $\mathrm{P} 1$ in the amount of $0.25 \%$ and $\mathrm{P} 2$ in the amount of $0.1 \%$ allows to obtain a product with structure more resistant to mechanical stress (mixing, pumping). Positive influence of addition of the preparations is evidenced by the smallest values of viscosity loss factor $(11 \pm 1$ and $19 \pm 1 \%, \mathrm{p}<0.05)$ and 
mechanical stability factor $(1.1 \pm 0.1$ and $1.2 \pm 0.1$, $\mathrm{p}<0.05)$ with the most pronounced thixotropic properties (the structure recovery ratio was $79 \pm 2$ and $77 \pm 1 \%$ $(\mathrm{p}<0.05)$ for the preparations $\mathrm{P} 1$ and $\mathrm{P} 2$, respectively). The samples with the addition of $\beta$-glucan-containing preparations $\mathrm{P} 1$ at a dosage of $0.25 \%$ and $\mathrm{P} 2$ at a dosage of $0.1 \%$ showed the highest structural and mechanical indicators. Therefore, we can conclude that the addition of the preparations $\mathrm{P} 1(0.25 \%)$ and $\mathrm{P} 2(0.1 \%)$ had a positive effect on the structure and consistency of the product $(\mathrm{p}<0.05)$, while the addition of the preparations P1 $(0.1 \%)$ and P3 $(0.1$ and $0.25 \%)$ had no significant effect on the same parameters $(\mathrm{p}>0.05)$.

The results of the sensory evaluation of yogurt samples are shown in Table 5.

Table 5

Sensory evaluation of yogurt samples

\begin{tabular}{lccccc}
\hline & \multicolumn{5}{c}{ Evaluation of the sample, points } \\
\cline { 2 - 6 } Sample & Taste & Odour & Colour & $\begin{array}{c}\text { Consis- } \\
\text { tency }\end{array}$ & $\begin{array}{c}\text { Appea- } \\
\text { rance }\end{array}$ \\
\hline Control & 5.0 & 5.0 & 5.0 & 5.0 & 5.0 \\
P1- 0.1\% & 4.9 & 5.0 & 3.9 & 4.5 & 4.8 \\
P1- 0.25\% & 4.8 & 5.0 & 3.8 & 4.7 & 4.8 \\
P2- 0.1\% & 5.0 & 5.0 & 4.7 & 4.9 & 5.0 \\
P3- 0.1\% & 4.6 & 4.7 & 3.4 & 3.6 & 4.4 \\
P3- 0.25\% & 4.5 & 4.7 & 3.2 & 3.5 & 4.1 \\
\hline
\end{tabular}

According to the data obtained the addition of most preparations (except P2) negatively influenced the colour of the final products $(\mathrm{p}>0.05)$.

Addition of P2 in concentration of $0.1 \%$ resulted in a slight change in colour from white to light beige. The problem of coloration can be solved by masking it with fruit filling or food colouring.

When using water-insoluble $\beta$-glucans (P1 and P3) in high dosages, heterogeneity of consistency (especially for P3) was detected. Insoluble particles of the preparation were precipitating during the fermentation process. It is possible to eliminate this drawback by adding a thickener such as pectin, guar gum, agar-agar, both in pure form and in the mixtures.

Presence of water-soluble $\beta$-glucans in preparation $\mathrm{P} 1$, which, as it was shown in Tables 4 and 5 are improving rheological and sensory properties of yogurts, probably can explain better performance of $\mathrm{P} 1$ in comparison to preparation P3.

Our results correspond to the results of other authors. Results of using fungal $\beta$-glucans in fortification of yogurt showed that the $\mathrm{pH}$ value and titratable acidity were not affected by the addition of different levels of glucans $(0.3 \%, 0.4 \%$ and $0.5 \%)$, when Streptococcus salivarious subsp. thermophilus and Lactobacillus delbrueckii subsp. bulgaricus were used as yogurt cultures (Pappa et al., 2018). When incorporating powdered brewer's yeast $\beta$-glucans into yogurt at concentrations $(0.2-0.8 \% \mathrm{wt} / \mathrm{wt})$, the titratable acidity remained unaffected, textural properties showed a gradual increment of hardness, adhesive force, and cohesiveness with increasing $\beta$-glucan concentration (Raikos et al., 2018). In comparison with the non-fat yogurt without $\beta$-glucan (Mejri et al., 2014), the application of yeast $\beta$-glucan in yogurt improved the rheological properties and the physical stability of the product.

\section{Conclusions}

The results of the study show that the addition of $\beta$-glucan preparations obtained from the submerged biomass of the culture of the fungus $P$. ostreatus (Jacq: Fr.) P. Kumm did not have a significant effect $(p>0.05)$ on the values of titratable acidity in the production of yogurt. The effect on the structural and mechanical parameters of the product depended on the form and dosage of the preparation. In this case, it is possible to assume improving the consistency of the product, since the structural and mechanical characteristics of the experimental samples exceeded the corresponding characteristics of the control sample. Samples of yogurt fortified with preparation P2 had the best sensory characteristics from the experimental samples, taking into account a complex of all tested indicators. Thus, from the point of view of obtaining a product with the highest consumer properties, preference should be given to preparation $\mathrm{P} 2$ in the amount of $0.1 \%$ (weight).

\section{References}

1. Antontceva E., Sorokin S., Shamtsyan M., Krasnikova L. (2018) Influence of Pleurotus ostreatus preparations on fermentation products of lactic acid cultures. Journal of Hygienic Engineering and Design, Vol. 22, p. 47-52.

2. Bashir K.M.I., Choi J.S. (2017) Clinical and physiological perspectives of $\beta$-glucans: The past, present, and future. International Journal of Molecular Sciences, Vol. 18(9), p. 2-48.

3. Bhaskar D., Khatkar S. K., Chawla R., Panwar H., Kapoor S. (2017) Effect of $\beta$-glucan fortification on physico-chemical, rheological, textural, colour and organoleptic characteristics of low fat dahi. Journal of Food Science and Technology, Vol. 54(9), p. 2684-2693.

4. Carrasco-González J.A., Serna-Saldívar S.O., GutiérrezUribe J.A. (2017) Nutritional composition and nutraceutical properties of the Pleurotus fruiting bodies: Potencial use as food ingredient. Journal of Food Composition and Analysis, Vol. 58, p. 69-81.

5. Facchini J.M., Alves E.P., Aguilera C., Gern R.M.M., Silveira M.L.L., Wisbeck E., Furlan S.A. (2014) Antitumor activity of Pleurotus ostreatus polysaccharide fractions on Ehrlich tumor and Sarcoma 180. International Journal of Biological Macromolecules, Vol. 68, p. 72-77.

6. Giavasis I. (2014) Bioactive fungal polysaccharides as potential functional ingredients in food and nutraceuticals. Current Opinion in Biotechnology, Vol. 26, p. 162-173.

7. Hozova B., Kuniak L., Kelemenova B. (2004) Application of beta-D-glucans isolated from mushrooms Pleurotus ostreatus (Pleuran) and Lentinus edodes (Lentinan) for increasing the bioactivity of yoghurts. Czech Journal of Food Sciences-UZPI (Czech Republic), Vol. 22(6), p. 204-214.

8. Jesenak M., Majtan J., Rennerova Z., Kyselovic J., Banovcin P., Hrubisko M. (2013) Immunomodulatory effect of pleuran ( $\beta$-glucan from Pleurotus ostreatus) in children with recurrent respiratory tract infections. International Immunopharmacology, Vol. 15(2), p. 395-399. 
9. Khan A.A., Gani A., Masoodi F.A., Mushtaq U., Silotry Naik A. (2017) Structural, rheological, antioxidant, and functional properties of $\beta$-glucan extracted from edible mushrooms Agaricus bisporus, Pleurotus ostreatus and Coprinus attrimentarius. Bioactive Carbohydrates and Dietary Fibre, Vol. 11, p. 67-74.

10. Khan M.A., Tania M. (2012) Nutritional and medicinal importance of Pleurotus mushrooms: An overview. Food Reviews International, Vol. 28(3), p. 313-329.

11. Khorshidian N., Yousefi M., Shadnoush M., Mortazavian A.M. (2018) An overview of $\beta$-glucan functionality in dairy products. Current Nutrition \& Food Science, Vol. 14(4), p. 280-292.

12. Lavelli V., Proserpio C., Gallotti F., Laureati M., Pagliarini E. (2018) Circular reuse of bio-resources: The role of: Pleurotus spp. in the development of functional foods. Food and Function, Vol. 9(3), p. 1353-1372.

13. Llauradó G., Morris H.J., Tamayo V., Lebeque Y., Beltrán Y., Marcos J., Bermúdez R.C. (2015) Haematopoiesis radioprotection in Balb/c mice by an aqueous mycelium extract from the Basidiomycete Pleurotus ostreatus mushroom. Natural Product Research, Vol. 29(16), p. 1557-1561.

14. McCleary B.V., Draga A. (2016) Measurement of $\beta$-glucan in mushrooms and mycelial products. Journal of AOAC International, Vol. 99(2), p. 364-373.

15. Mejri W., Bornaz S., Sahli A. (2014) Formulation of nonfat yogurt with $\beta$-glucan from sent brewer's yeast. Journal of Hygienic Engineering and Design, Vol. 8, p.163-173.

16. Novak M., Vetvicka V. (2008) $\beta$-glucans, history, and the present: Immunomodulatory aspects and mechanisms of action. Journal of Immunotoxicology, Vol. 5(1), p. 47-57.

17. Pappa E.C., Kondyli E., MacNaughtan W., Kakour A., Nesseris K., Israilides C. (2018) Quality and sensory properties of reduced fat yoghurt made with addition of $\beta$-glucans. Food and Nutrition Sciences, Vol. 9, p. 390-402.

18. Pasnik J., Ślemp A., Cywinska-Bernas A., Zeman K., Jesenak M. (2017) Preventive effect of pleuran ( $\beta$-glucan from Pleurotus ostreatus) in children with recurrent respiratory tract infections - Open-label prospective study.
Current Pediatric Research, Vol. 21(1), p. 99-104.

19. Radzki W., Ziaja-Sołtys M., Nowak J., Rzymowska J., Topolska J., Sławińska A., Michalak-Majewska M., Zalewska-Korona M., Kuczumow, A. (2016) Effect of processing on the content and biological activity of polysaccharides from Pleurotus ostreatus mushroom. LWT-Food Science and Technology, Vol. 66, p. 27-33.

20. Raikos V., Grant S. B., Hayes H., Ranawana V. (2018) Use of $\beta$-glucan from spent brewer's yeast as a thickener in skimmed yogurt: Physicochemical, textural, and structural properties related to sensory perception. Journal of Dairy Science, Vol. 101(7), p. 5821-5831.

21. Shamtsyan M., Antontceva E., Panchenko A. Petrischev N. (2014) Hyperlipidemic and hypocholesterolic action of submerge cultured mushrooms. Journal of Hygienic Engineering and Design, Vol. 7, p. 96-99.

22. Sorokin S., Tufeanu R., Shamtsyan M., Mironescu I. D., Antonceva E., Tița O. (2016) Physico-chemical and rheological properties of yogurt with added Pleurotus ostreatus biomass treated with ethanol. Journal of EcoAgriTourism, Vol. 12(2), p. 39-46.

23. Tong H., Xia F., Feng K., Sun G., Gao X., Sun L., Sun X. (2009) Structural characterization and in vitro antitumor activity of a novel polysaccharide isolated from the fruiting bodies of Pleurotus ostreatus. Bioresource Technology, Vol. 100(4), p. 1682-1686.

24. Vannucci L., Krizan J., Sima P., Stakheev D., Caja F., Rajsiglova L., Horak V., Saieh M. (2013) Immunostimulatory properties and antitumor activities of glucans (Review). International Journal of Oncology, Vol. 43(2), p. 357-364.

25. Vital A.C.P., Goto P.A., Hanai L.N., Gomes-daCosta S.M., de Abreu Filho B.A., Nakamura C.V., Matumoto-Pintro P.T. (2015) Microbiological, functional and rheological properties of low fat yogurt supplemented with Pleurotus ostreatus aqueous extract. LWT-Food Science and Technology, Vol. 64(2), p. 1028-1035. 